\title{
Stock Splits and Cash Flows: A New Test of the Signaling Hypothesis
}

\author{
fulie Fitzpatrick and Tai David Yi
}

Julie Fitzpatrick (Julie.Fitzpatrick@fredonia.edu) and Tai David Yi (yit@fredonia.edu) are Associate Professors of Finance, Department of Business Administration, School of Business, SUNY Fredonia, 280 Central Avenue, Fredonia, NY 14063. Correspondence concerning this paper should be addressed to Julie Fitzpatrick.

\begin{abstract}
We revisit the signaling hypothesis by examining whether stock splits contain information about future Operating Cash Flow (OCF) and Free Cash Flow (FCF) over the period 1963-2014. We use cash flows because they may be viewed as "cleaner" measures of performance (Barber and Lyon (1996)), and recent research finds that cash flow measures are better predictors of stock returns than various income statement-based measures (Foerster et al. (2017)). Logistic regression results indicate that split firms have significantly higher market-to-book, price, prior year returns, OCF, and FCF than non-split firms. We provide evidence that OCF and FCF are significant split factor determinants even after controlling for price, market value of equity, and Runup, although results differ for dividend- and non-dividend payers. Our results indicate
\end{abstract}




\section{The BRC Academy Journal of Business Vol. 8, No. 1}

that the split factor contains information about future stock price performance for split firms that pay dividends. Finally, we find that the coefficient for the regression residual is significantly positively related to various measures of current and future profitability, providing support for the signaling hypothesis.

Keywords: stock splits, signaling hypothesis, operating cash flow, free cash flow

DOI: http://dx.doi.org/10.15239/j.brcacadjb.2018.08.01.ja01

\section{INTRODUCTION}

Although stock splits should, in theory, have no net effect on shareholder wealth, prior research finds significant positive abnormal returns around stock split announcements (Grinblatt et al. 1984, Lamoureux and Poon 1987, Desai and Jain 1997, Byun and Rozeff 2003). Two main hypotheses have been advanced and empirically tested to explain firms' motives for stock splits.

According to the trading range hypothesis, a firm undertakes a stock split to bring its share price down to an optimal trading range. First proposed by Copeland (1979), this theory argues that stock splits make it easier for small investors to purchase shares of stock and thus may increase liquidity. For example, when Apple, Inc. announced a 7-for-1 stock split in 2014, CEO Tim Cook said "we want Apple stock to be more accessible to a larger number of investors." While many firms allude to this motive when announcing stock splits, the empirical evidence related to greater liquidity is generally inconclusive (Copeland 1979, Schultz 2000, Easley et al. 2001, Goyenko et al. 2005).

Another common explanation for stock splits is the signaling theory. According to this theory, managers are assumed to have better information than investors concerning the firm's future prospects. The signaling theory posits that firms split their shares to reveal managers' favorable information about the firm's future prospects. In other words, stock 
splits can be used to reduce information asymmetry between managers and investors.

In one of the first studies of stock splits, Fama, Fisher, Jensen, and Roll (1969) examine splits from 1927 to 1959. They find that splitting firms experience abnormal returns of about $30 \%$, on average, in the two years preceding the stock split. In addition, they argue that the positive announcement returns are due to revised expectations concerning future dividends.

Several researchers provide empirical evidence to support the signaling hypothesis. Lakonishok and Lev (1987) find higher short-term earnings growth for split firms relative to comparable non-split firms. McNichols and Dravid (1990) find that the split factor signals a manager's private information about future earnings. Ikenberry and Ramnath (2002) find that "splitting firms have an unusually low propensity to experience a contraction in future earnings." Ikenberry, Rankine, and Stice (1996), based on their findings of an average announcement return of $3.38 \%$, and post-split excess returns of $7.93 \%$ in the first year and $12.15 \%$ in the first three years, conclude that "the evidence suggests that splits realign prices to a lower trading range, but managers self-select by conditioning the decision to split on expected future performance."

More recently, Chen et al. (2011) examine post-split announcement annual earnings of split and comparable non-split firms. They find that "split firms significantly outperform their matched sample in the postsplit period" and interpret this as "direct evidence that splits in aggregate contain information about positive future earnings growth" (p. 2,455).

Other research fails to support the signaling hypothesis. Asquith, Healy, and Palepu (1989) report large increases in earnings and returns before, but not after, stock splits. More recently, Huang, Liano, and Pan (2006) document a negative relationship between stock splits and various measures of future earnings. 
While many studies have examined the signaling hypothesis, the empirical tests to date focus almost exclusively on earnings as the measure of future performance with mixed results. Using a sample of 11,157 and 185,424 split and non-split observations, respectively, over the period 1963-2014, we revisit the signaling hypothesis by investigating whether a firm's split factor choice conveys private information regarding the firm's future performance. Unlike prior studies, however, we use cash flows as our measure of performance.

In theory, cash flows are a better measure of performance than earnings for several reasons. In Valuation: Measuring and Managing the Value of Companies, Copeland et al. (2000) argue for the superiority of the Discounted Cash Flow (DCF) valuation approach compared to the accounting valuation approach with its focus on a measure of earnings (usually, Net Income). Widely used by practitioners, Discounted Cash Flow valuation models estimate firm value by discounting expected future cash flows at a rate that reflects the risk of those cash flows. Accounting earnings are useful for valuation "only when earnings is a good proxy for the expected long-term cash flow of the company (p. 72)." Moreover, "the DCF approach is strongly supported by research into how the stock markets actually value companies (p. 72).”

Barber and Lyon (1996) provide additional theoretical support for the use of cash flows in measuring performance. They argue that operating cash flow can be viewed as a 'cleaner' measure of operating performance because earnings include interest expense, special items, and income taxes, which can obscure operating performance, and operating cash flows represent the economic benefits generated by the firm.

Several empirical studies provide additional support for the use of cash flows. Biddle and Lindahl (1982) examine the stock price reaction of companies that switched from FIFO to LIFO. A change from FIFO to LIFO accounting generally results in higher costs (since more recent inventory is expensed first) and therefore lower accounting earnings. However, since lower earnings decreases taxable income and taxes paid, 
the result is an increase in cash flow. The authors find that switching from FIFO to LIFO results in a higher share price, a result that is consistent with DCF valuation. McConnell and Muscarella (1985) find positive (negative) returns associated with announcements of increases (decreases) in capital expenditures, a result that is also consistent with a DCF model since increased capital expenditures lower short-term earnings but may increase future cash flows. Copeland and Lee (1988) examine stock market reaction to exchange offers and stock swaps. Their results show that only the transaction's effect on firm leverage, not earnings-per-share (EPS), affects announcement returns. Since only transactions that increased leverage resulted in higher stock price reactions, the authors conclude that leverage-increasing transactions could signal strong future cash flows.

Two recent studies highlight the importance of cash flows in predicting stock returns. Hou et al. (2011) study monthly returns from 1981 to 2003 for over 27,000 global stocks and find that cash-based measures (i.e., cash flow-to-price) capture significant time-series variation in returns. Foerster et al. (2017) examine returns of S\&P 1500 stocks from 1994 to 2013 and find that cash flow measures are better predictors of stock returns than various income statement-based measures. "Commonly used income statement-related metrics, including return on assets and earnings yield, have some predictive power, but in general, cash-based measures are superior to measures of operating profitability (p. 27)."

Following McNichols and Dravid (1990), we develop a signaling model to examine whether a firm's split factor contains private information regarding the firm's future prospects. If the signaling hypothesis correctly describes a firm's motives for a stock split, and a stock split is a signal of higher future cash flows, then pre-split cash flows may determine a firm's split factor. Our results indicate that OCF and FCF are significant split factor determinants even after controlling for Price, MV, and Runup, although important differences exist between dividend- and non-dividend payers. 
Next, holding pre-split price, firm size, and Runup (i.e., percentage change in price from the prior year) constant, are stock price changes significantly related to the signal of manager's private information? We find that the change in a firm's annual return from the prior year $(\triangle \mathrm{RET})$ is significantly positively associated with its split factor for all split firms and dividend payers during the full sample period and sub-sample periods, and significant at a level of $5 \%$ for non-dividend payers. Overall, this finding suggests that investors pay more, expecting an increase in OCF and FCF that is revealed through a manager's choice of a split factor, a result that is consistent with McNichols and Dravid (1990).

Finally, we examine whether the unspecified split factor, i.e., a manager's private information, is associated with various measures of future profitability. We document that the coefficient for the regression residual is significantly positively related to all of the profitability measures, including OCF/FCF, at the current and next periods for all split firms and dividend payers, and at least at the current period for nondividend payers over the full sample period. Thus, our results indicate that the split factor conveys a manager's private information of unexpected profitability for dividend and non-dividend payers at least in the near future regardless of the profitability measure.

The rest of the paper is organized as follows. The sample of split and non-split firms is described in the Data and Descriptive Statistics section. We document firm-specific variables that predict stock splits in the Logit Model section. In the Signaling Model section, we provide evidence on characteristics of dividend and non-dividend paying split firms, determinants of the split factor, and whether the market uses it for return and profitability prediction. The last section summarizes and concludes. 


\section{Data And Descriptive Statistics}

We use the CRSP monthly data to identify firms that announced a stock split during the time period 1963 (the first year that stockholders' equity is available on COMPUSTAT) through 2014. Split firms are identified as those with CRSP distribution code of 5523 and a split factor of at least five for four. ${ }^{1}$ Stock prices and monthly returns of split and non-split firms are retrieved from the CRSP monthly U.S. Stock database, and financial data are retrieved from the COMPUSTAT annual database. ${ }^{2}$ To be included in the sample, a firm must have: (1) positive total assets; (2) positive total shareholders' equity; and (3) price and annual return data available. Given data availability and our sample selection criteria, the total number of split and non-split observations are 11,157 and 185,424, respectively, over the entire sample period. Following Minnick and Raman (2014), we initially divide the full sample period into eight sub-periods. As indicated in Table 1, the number of split firms peaked during the $1983-1987$ period. While the number of split firms generally increased through the $1993-1997$ period, it sharply declined during the most recent period (2009 to 2014).

We first examine differences in firm-specific characteristics of split and non-split firms. For each firm we use CRSP and COMPUSTAT data to compute ROE, MB (market-to-book value of equity), size, price, return, DP (dividend payer), OCF (operating cash flow), and FCF (free cash flow). ROE is defined as operating income before depreciation over total stockholders' equity. MB is the market value of equity divided by total stockholders' equity. Size is defined as the natural log of total assets. Return is the annualized geometric return. DP is an indicator variable which equals one if the dividend payment, the sum of common dividends and preferred dividends, is greater than zero. Otherwise, DP equals zero. OCF is the proportion of operating cash flow to total assets, where operating cash flow is measured by operating income before depreciation. FCF is the proportion of free cash flow to total assets, where free cash flow is measured by operating income before depreciation minus the sum 
of total income taxes, total interest and related expense, and common dividends and preferred dividends.

$\mathrm{ROE}, \mathrm{MB}, \mathrm{OCF}$, and FCF are winsorized at $5 \%$ and $95 \%$ to minimize outliers present in the data. Values below $5 \%$ are replaced by the value at $5 \%$, and values above $95 \%$ are replaced by the value at $95 \%$. Table 2 reports the means and standard deviations of each variable for split and non-split firms over the full sample period and for the sub-sample periods of 1963-1992 and 1993-2014. Note that the first and last four subperiods in Table 1 are combined to create the 1963-1992 and 1993-2014 sub-periods, respectively. We conduct a two-sample test of group means for each variable. The two-sample tests indicate that the means of all variables are significantly different from zero at the 1 percent level.

\section{PREVIEW COMPLETE}

This completes the limited preview of this paper. Please visit the link below to purchase.

\section{Citation Information}

Fitzpatrick, Julie, and Tai David Yi. "Stock Splits and Cash Flows: A New Test of the Signaling Hypothesis." The BRC Academy fournal of Business 8, no. 1 (2018): 1-22. http://dx.doi.org/10.15239/j.brcacadjb.2018.08.01.ja01 


\section{Notes}

1. CRSP split factor (facpr) is greater than or equal to 0.25 .

2. The CRSP data includes monthly price, return, and shares outstanding, and the Compustat data includes total assets, total stockholders' equity, common dividends, preferred dividends, net income, operating income before depreciation, total income taxes, and total interest and related expense. 